\title{
Co-transmission of Conduct Problems with Attention Deficit Hyperactivity Disorder: familial evidence for a distinct disorder
}

\author{
H. Christiansen*1 ${ }^{1}$, W. Chen*2, R. D. Oades ${ }^{1}$, P. Asherson ${ }^{3}$, E. A. Taylor ${ }^{3}$, J. Lasky-Su ${ }^{4}$, K. Zhou ${ }^{3}$, \\ T. Banaschewski ${ }^{5}$, C. Buschgens ${ }^{6}$, B. Franke ${ }^{6}$, I. Gabriels ${ }^{7}$, I. Manor ${ }^{8}$, R. Marco ${ }^{9}$, U. C. Müller ${ }^{10}$, \\ A. Mulligan ${ }^{11}$, L. Psychogiou ${ }^{2}$, N. N. J. Rommelse ${ }^{12}$, H. Uebel $^{13}$, J. Buitelaar ${ }^{6}$, R. Ebstein ${ }^{14}$, J. \\ Eisenberg $^{14}$, M. Gill ${ }^{11}$, A. Miranda ${ }^{9}$, F. Mulas ${ }^{9}$, H. Roeyers ${ }^{7}$, A. Rothenberger ${ }^{13}$, J. A. Sergeant ${ }^{12}$, \\ E. J. S. Sonuga-Barke ${ }^{2}$, H-C. Steinhausen ${ }^{10}$, M. Thompson ${ }^{2}$ and S. V. Faraone ${ }^{4}$ \\ *The first two authors contributed equally to this paper:
}

\section{Journal of Neural Transmission, 8, 122-131.}

This is the reformatted manuscript submitted - prior to publication in its final form at DOI 10.1007/s00702-007-0837-y

1 Clinic for Child \& Adolescent Psychiatry and Psychotherapy, University of Duisburg-Essen, Essen, Germany

School of Psychology, University of Southampton, Southampton, UK

3 MRC Social Genetic Developmental \& Psychiatry Centre, Institute of Psychiatry, London, UK

4 Departments of Psychiatry, Neuroscience and Physiology, SUNY Upstate Medical University, Syracuse, NY, U.S.A.

5 Department of Child and Adolescent Psychiatry and Psychotherapy, Central Institute of Mental Health, J 5, 68159 Mannheim, Germany

6 Department of Psychiatry, University of Nijmegen Medical Center, Nijmegen, The Netherlands

7 Department of Experimental Clinical and Health Psychology, Ghent University, Belgium

8 Geha MHC, Petach-Tikva, Israel

9 Department of Developmental \& Educational Psychology, University of Valencia, Spain

10 Department of Child \& Adolescent Psychiatry, University of Zurich, Switzerland

11 Department of Psychiatry, Trinity Centre for Health Sciences, St. James's Hospital, Dublin, Ireland

12 Vrije Universiteit, De Boelelaan 11051081 HV, Amsterdam, The Netherlands

13 Department of Child and Adolescent Psychiatry, University of Göttingen, Germany

14 S. Herzog Memorial Hospital, Jerusalem, Israel

Key Words: ADHD, Conduct Problems, Conduct Disorder, Comorbidity, Diagnosis, Oppositional Defiant Disorder, Relative Risk

Abbreviations: ADHD, Attention-deficit/hyperactivity disorder; ADHDct, ADHD-combined type; $C D$, Conduct Disorder; CP, Conduct Problems; CP/TRS, Conners parent/teacher rating scale; DSM-IV, Diagnostic and statistical Manual of the American Psychiatric Association, $4^{\text {th }}$ version; ; ICD-10, International Classification of Diseases, $10^{\text {th }}$ version; IMAGE, International Multicentre ADHD Genetics study; ODD, Oppositional Defiant Disorder; PACS, Parental Account of Children's Symptoms; SDQ, Strengths and difficulties questionnaire

\section{Acknowledgements:}

This work was funded by NIMH Grant ROIMH062873 to S. V. Faraone. Additional sources of financial support for data collection reported in this paper included the Medical Research Council (London; Kuntsi); Economic and Social Research Council, Southampton Primary Care Trust, HOPE and the University of Southampton (Southampton; Sounga-Barke and Thompson); Catherijne Foundation and the UMC St Radboud (Nijmegen; Buitelaar). We thank all the families that have generously provided clinical information for this research.

Correspondence: Robert D. Oades, Clinic for Child and Adolescent Psychiatry and Psychotherapy, University of Duisburg-Essen, Virchowstr. 174, 45147 Essen, Germany. Email: robert.oades@unidue.de 


\section{Summary.}

Common disorders of childhood and adolescence are attention-deficit/ hyperactivity disorder (ADHD), oppositional defiant disorder (ODD) and conduct disorder (CD). For one to two cases in three diagnosed with ADHD the disorders may be comorbid. However, whether comorbid conduct problems (CP) represents a separate disorder or a severe form of ADHD remains controversial. We investigated familial recurrence patterns of the pure or comorbid condition in families with at least two children and one definite case of DSM-IV ADHDct (combinedtype) as part of the International Multicentre ADHD Genetics Study (IMAGE). Using case diagnoses (PACS, parental account) and symptom ratings (Parent/Teacher Strengths and Difficulties [SDQ], and Conners Questionnaires [CPTRS]) we studied 1009 cases (241 with ADHDonly and 768 with ADHD+CP), and their 1591 siblings. CP was defined as $\geq 4$ on the SDQ conduct-subscale, and $T \geq 65$, on Conners' oppositional-score. Multinomial logistic regression was used to ascertain recurrence risks of the pure and comorbid conditions in the siblings as predicted by the status of the cases. There was a higher relative risk to develop ADHD+CP for siblings of cases with ADHD+CP (RRR $=4.9 ; 95 \% \mathrm{Cl}: 2.59-9.41) ; p<.001)$ than with ADHDonly. Rates of ADHDonly in siblings of cases with $A D H D+C P$ were lower but significant $(R R R=2.9$; 95\% Cl: 1.6-5.3, $\mathrm{p}<.001)$. Children with 'ADHD+CP' scored higher on the Conners ADHDct symptom-scales than those with ADHDonly. Our finding that $A D H D+C P$ can represent a familial distinct subtype possibly with a distinct genetic etiology is consistent with a high risk for cosegregation. Further, ADHD+CP can be a more severe disorder than ADHDonly with symptoms stable from childhood through adolescence. The findings provide partial support for the ICD-10 distinction between hyperkinetic disorder (F90.0) and hyperkinetic conduct disorder (F90.1).

\section{Introduction}

Attention-deficit/hyperactivity disorder (ADHD), characterized by the symptom clusters of hyperactivity, inattention, and impulsivity, develops in early childhood and frequently leads to social, academic, and occupational impairments. ADHD, conduct disorder (CD) and oppositional defiant disorder (ODD) are three common behavioral disorders in childhood. The syndromes occur separately but can be comorbid. Both genetic and environmental factors contribute to the expression of the single diagnosis and their aggregation in families with attention deficit (Nadder et al., 2002; Thapar et al., 2001) and antisocial disorders (Burt et al., 2005; Faraone et al., 1995). Yet it remains controversial, whether the co-occurrence of the disorders in individuals (e.g. ADHD+CD) aggregates in families, and represents a separate heritable entity.
Taylor and colleagues (1991) proposed that comorbid $A D H D+C D$ may be a separate condition arising mainly out of poor impulse control, and exacerbated by high parental expressed emotion. More recently Drabick et al. (2006) also reported hostile, inconsistent, and detached parenting to be associated with $C D$ symptoms in ADHD children. Consistent with this Hurtig et al. (2007) reported that adolescents with comorbid $C D$ exhibited more severe symptoms of ADHD than those without $C D$, and were more likely to come from non-intact families with disaffected mothers. On the other hand the clinical findings of Schachar and Wachsmuth (1990) indicated that forms of ADHD with and without aggression were separate and distinct. Halperin (1991) supported this viewpoint with a description of separate neuropsychological correlates for the two forms. The purely hyperactive type was more inattentive and 
the mixed hyperactive/aggressive type was more impulsive. Taylor (1998) however accommodated these findings by suggesting that they represent alternative trajectories leading to aggressive ADHD children or children with combined type ADHD.

ADHD is a highly heritable behavioral condition for which recent estimates suggest a 4-8 fold increase in risk for the condition in first-degree relatives of ADHD cases compared to those in the general population (Faraone et al., 2000a; Willcutt et al., 2000). Numerous studies of parentand teacher-rated symptoms in twins demonstrate the predominant role of genetic factors on the familial prevalence for ADHD symptoms with heritability estimates of $60-90 \%$ (Faraone et al., 2005b; Thapar et al., 1999).

ODD, like ADHD, typically has an onset in early childhood, but is characterized by temper tantrums, irritability, spiteful attitudes, frequent arguments, anger, defiance of adults' authority, and excessive blaming and intentional annoyance of others (Dick et al., 2005). ODD cases differ from those with comorbid $C D$ in their social impairment and the prevalence of mood disorders (Greene et al., 2002). CD usually develops later than ODD, and is characterized by antisocial behaviors covering the symptoms of four domains (e.g. theft, lying, truancy, threatening and aggressive behavior towards people and animals, fire setting, and destruction of property, (Nock et al., 2006). ODD often precedes $C D$ as children reach adolescence, but not all those with $C D$ have a history of ODD (Lahey et al., 2000). Prevalence rates for CD (7-12\% in males) approximate those for ADHD (Kratzer and Hodgins, 1997) (Faraone et al., 2003; Nock et al., 2006), but heritability estimates (about 40\%) are more modest than for ADHD (Ehringer et al., 2006).

Previous studies of whether there are separate or overlapping etiologies for the disorder of ADHD with oppositionality (ODD and/or CD) from ADHDonly have used familial aggregation, longitudinal, and genetic designs to clarify the patterns of comorbidity found in clinical data. We outline briefly the most relevant findings.

Family studies suggest that $A D H D+C D$ represents a specific subtype of disorder with familial risk factors independent of ADHD alone (Faraone et al., 1991; Faraone et al., 2000b; Faraone and Biederman, 1997; Frick et al., 1991; Lahey et al., 1988; Stewart et al., 1980; Szatmari et al., 1993). August and Stewart (1983) found that, among hyperactive children, a family history of antisocial behavior predicted more CD symptoms in the child and a greater risk of $C D$ to siblings. In contrast those without a family history of antisocial problems showed attentional difficulties, but not symptoms of $C D$ and did not have siblings with CD symptoms. August et al. (1983) also found in a four-year follow-up that baseline childhood CD symptoms predicted the degree of $C D$ shown in early adolescent hyperactive boys. Thus longitudinal data support the predictive validity of the classification of a distinct subtype.

Lahey et al. (1988) also reported higher rates of antisocial disorders, depression and substance abuse among relatives of $A D H D+C D$ cases compared to cases of ADHDonly. In another study, the mothers of $A D H D+C D$ children were found to have higher rates of psychopathology than the mothers of children with ADHDonly (Lahey et al., 1989). Similarly Frick et al. (1991) noted that parents of $A D H D+C D$ children had higher rates of childhood hyperactivity, $C D$ and substance abuse than parents of children with ADHDonly. Faraone et al. (1991) compared families with Attention Deficit Disorder (ADD) cases with those of normal controls. They found an increased risk for antisocial disorders among the 
relatives of DSM-III ADD cases with CD and ODD, but not among the relatives of those with only $A D D$. In the families of $A D D+C D$ cases, $A D D$ and $C D$ co-segregated. These results suggested $A D D+C D$ might be distinct from ADD without CD.

\section{Twin Studies}

Early twin studies of juvenile delinquency found a low heritability with substantial but similar concordance rates for identical and fraternal twins, that were only marginally higher for the monozygotic twin (McGuffin and Gottesman, 1985). More recent twin studies suggest that the comorbidity of CD/ODD with ADHD is not only extensive (Simonoff et al., 1997), but it defines a more severe form of ADHD in terms of genetic loading (Dick et al., 2005; Silberg et al., 1996; Thapar et al., 2001).

The Virginia twin study (Silberg et al., 1996) found that the genes influencing variation in scores of hyperactivity were also responsible for the variation in conduct problems (CP), accounting for 76$88 \%$ of the correlation between scores (confirmed by Nadder et al., 2002). Thapar et al. (2001) examined categories of ADHD and $\mathrm{CP}$ based on parental ratings of symptoms in the DSM-III-R, ICD-10 and Rutter-A scales in 2082 twin-pairs. On the basis of a heritability estimate for $\mathrm{CP}$ of $47 \%$ and a shared environmental contribution of $36 \%$ they concluded that $A D H D+C P$ represents a more extreme variant of $A D H D$ in terms of genetic loading and clinical severity. The report from Vierikko et al. (2004) supports this position. They performed bivariate analyses on hyperactivity and aggression traits in a Finnish twin sample, and found that, in addition to significant genetic and environmental influences specific to each behavior, aggression and hyperactivityimpulsivity shared a common genetic and environmental etiology. Both studies imply that comorbidity represents a more severe form of ADHD.
The Minnesota study of $178211 \mathrm{y}$-old twins (Burt et al., 2005), though in partial agreement, went even further. On the basis of bivariate analyses of hyperactivity and aggression traits, they reported a substantial shared environmental factor with only marginal genetic contributions to the etiology. However, this result varied significantly with the source of the information analyzed (i.e. children's selfratings $v s$. ratings by the mother). These twin studies provide some support for the proposal that $A D H D+C P$ is a distinct subtype, but vary quite widely on the heritable or environmental contribution.

\section{The CP distinction}

Several studies suggested that apart from a positive family history, the severity of antisocial behavior plays a major role in correlations of ADHD with comorbid externalizing behavior. For example, chronic CP was differentiated from persistent low CP by risk factors in child, parenting, and family domains (Shaw et al., 2005). This affects whether ADHD+CP is accepted as a more severe variant of $A D H D$ than ADHDonly, as widely advocated (Banaschewski et al., 2003; Jensen et al., 1997; Kuhne et al., 1997; Levy et al., 2006).

The validity of the $C P$ dimension in the present study depends in part on it being a modest reflection of the category of $C D$. There is in fact evidence that the degree of $C D$ is under separate environmental and familial influences. Levy et al. (2006) differentiated $C D$ into the expression of symptoms to a mild (like ODD), moderate (modest CD: e.g. lying) or extreme degree (severe CD: e.g. fire-setting). They studied $A D H D+C D$ in the Australian twin study and found a best fit for the 3-level model of CD in terms of additive genetic, shared and non-shared environmental factors (ACEmodel). Extreme $C D$ was found to have a very high common environment factor, and a negligible effect of heredity. This indicates that growing-up in the same 
family has a strong influence on the development of extreme $C D$, but not so much on the appearance of ADHD or milder forms of $C D$. Also, the extreme form of $C D$ (as compared to mild or moderate $\mathrm{CD})$ was much less correlated with the expression of inattention and hyperactivity/impulsivity. Indeed, in a nontwin study based on 68 subjects with CD or $A D H D+C D$ diagnoses, the canonical correlation analysis of Mathias et al. (2007) describes an association for the less-thanextreme expression of $\mathrm{CP}$ with inattention and hyperactivity. Together these results imply that extreme $C D$ is a disorder distinct from mild and moderate CD. Importantly, milder conduct problems (CP) are more likely to be comorbid with ADHD and have a common biological etiology.

\section{The Present Study}

To test these competing hypotheses, a large sample of ADHD combined-type cases and their siblings from the IMAGE study were investigated. The combined type of ADHD is more prevalent than the inattentive or hyperactive-impulsive forms, and manifests comorbidity with $\mathrm{CP}$ more frequently than the other forms (Eiraldi et al., 1997). The sample consisting only of combined-type ADHD therefore minimizes the effects of confounding factors present in a sample of mixed ADHD subtypes. It is therefore particular suitable to test these competing hypotheses. Our aim was to test whether cases of ADHD+CP should be regarded as an etiologically and heritably separate condition, as endorsed by the ICD-10 classification.

Different hypotheses could account for the co-occurrence of $A D H D$ and ODD/CD (see table 1: evidence for each proposal is discussed in Faraone et al., 1997; Greene et al., 2002; Schachar and Tannock, 1995). However, diagnostic interviews (PACS) were not available for all siblings. As a category referring to $\mathrm{CP}$ was required for the whole sample of cases and siblings, we first validated the questionnaire ratings (e.g. Conners, Strengths and Difficulties) that were available for all subjects for representing an adequate measure of the behavioral problems related to $\mathrm{CD} / \mathrm{ODD}$ across the sample. Here the term CP is thus a broad category that allows for the occurrence of $C D$ and ODD. Having operationally defined and validated $\mathrm{CP}$ (see results), we sought to resolve predictions arising from four of the principle proposals (table 1) with a study of a large population of families with cases of ADHD and unaffected siblings recruited by the IMAGE genetics consortium (Asherson and the Image Consortium, 2004).

We would predict proposal 2. This suggests that comorbid $\mathrm{CP}$ and ADHD, represented by $A D H D+C P$, is a distinct disorder: cases with ADHDonly will tend to have siblings with ADHDonly, while cases with $A D H D+C P$ will likely have siblings with $A D H D+C P$. But if $A D H D+C P$ is merely an extreme variant of ADHD (proposal 3), then cases with comorbid $A D H D+C P$ will have many siblings with ADHDonly, but also many siblings with $A D H D+C P$. However, one can conceive ADHD and $C P$ to be separate entities. If they share environmental risk factors (proposal 4) then ADHDonly cases should have many siblings with ADHDonly, many $A D H D+C P$ cases will have siblings with $A D H D+C P$, and there should also be a high number of siblings with only CP. If however, ADHD and $\mathrm{CP}$ are etiologically independent with only a chance concordance (proposal 1), then the distribution of the disturbances of siblings of cases with ADHD+CP will be lower and evenly distributed across the subgroups compared to a more marked likelihood of ADHDonly cases having siblings with ADHDonly. The outcome of the analysis has nosological implications. The American Psychiatric Association maintains these disorders as separate entities (DSM-IV, 1994: ADHD 314.x, CD 
312.8, ODD 313.8), while the World Health Organization recognizes a distinct subtype of 'hyperkinetic conduct disorder' (ICD10, 1991: F90.1) separate from 'simple attention-deficit hyperactivity disorder' (F90.0) and CD (F91.x).

In summary, to support the concept of $A D H D+C P$ as a distinct condition, we predict finding (i) a specific pattern of $A D H D+C P$ recurrence in siblings related to cases with ADHD+CP (proposal 2, reflecting cosegregation); (ii) there is no support for a shared environmental effect, as shown by the absence of an increased rate of CPonly in siblings of $A D H D+C P$ cases (proposal 4); and (iii) there is no evidence of increased ADHD loadings in siblings, as indicated by the absence of an increased rate of ADHDonly in the siblings of ADHD+CP cases (proposal 3) .

Table 1: Hypotheses on the familial association between ADHD and CP

\begin{tabular}{|c|c|c|c|c|c|c|}
\hline \multirow[t]{2}{*}{ Hypothesis } & \multirow{2}{*}{$\begin{array}{c}\text { Case } \\
\text { Diagnosis }\end{array}$} & \multicolumn{4}{|c|}{ Siblings Recurrence Risks } & \multirow[t]{2}{*}{ Cosegregation } \\
\hline & & $\begin{array}{l}\text { No } \\
\text { disorder }\end{array}$ & $\begin{array}{l}\text { ADHD } \\
\text { only }\end{array}$ & $\begin{array}{l}\mathrm{ADHD}+ \\
\mathrm{CP}\end{array}$ & $\begin{array}{l}\mathrm{CP} \\
\text { only }\end{array}$ & \\
\hline $\begin{array}{l}\text { 1. ADHD \& CP etiologically } \\
\text { independent, i.e. chance co- } \\
\text { occurrence }\end{array}$ & $\begin{array}{l}\text { ADHDonly } \\
\text { ADHD+CP }\end{array}$ & $\begin{array}{l}- \\
--\end{array}$ & $\begin{array}{l}++ \\
+\end{array}$ & $\begin{array}{l}-- \\
+\end{array}$ & $\begin{array}{l}-- \\
+\end{array}$ & No \\
\hline $\begin{array}{l}\text { 2. ADHD+CP as a distinct } \\
\text { condition from ADHDonly, } \\
\text { i.e. 'co-segregated' pattern }\end{array}$ & $\begin{array}{l}\text { ADHDonly } \\
\text { ADHD+CP }\end{array}$ & $\begin{array}{l}- \\
--\end{array}$ & $\begin{array}{l}+++ \\
+\end{array}$ & $\begin{array}{l}- \\
+++\end{array}$ & $\begin{array}{l}- \\
--\end{array}$ & Yes \\
\hline $\begin{array}{l}\text { 3. ADHD+CP as an extreme } \\
\text { severe variant of ADHD } \\
\text { i.e. common genetic etiology }\end{array}$ & $\begin{array}{l}\text { ADHDonly } \\
\text { ADHD+CP }\end{array}$ & $\begin{array}{l}-- \\
--\end{array}$ & $\begin{array}{l}+ \\
++\end{array}$ & $\begin{array}{l}-- \\
+++\end{array}$ & $\begin{array}{l}-- \\
--\end{array}$ & No \\
\hline $\begin{array}{l}\text { 4. ADHD \& CP Share common } \\
\text { environmental risk factors }\end{array}$ & $\begin{array}{l}\text { ADHDonly } \\
\text { ADHD+CP }\end{array}$ & $\begin{array}{l}-- \\
--\end{array}$ & $\begin{array}{l}++ \\
+\end{array}$ & $\begin{array}{l}-- \\
++\end{array}$ & $\begin{array}{l}-- \\
++\end{array}$ & No \\
\hline
\end{tabular}

' $++{ }^{\prime} /{ }^{\prime} '$ = high/intermediate risk for disorder, and '--' = no increased risk for disorder, $v s$. controls ADHD $=$ Attention-Deficit/Hyperactivity Disorder,

$\mathrm{ADHD}+\mathrm{CP}=\mathrm{ADHD}$ with Conduct Problems (CP); ADHDonly $=\mathrm{ADHD}$ without $\mathrm{CP}$

\section{Methods and materials}

\section{Participants}

This study is based on 3229 offspring from 1187 fathers and 1341 mothers. Entry criteria for the cases included a diagnosis of DSM-IV 'combined subtype' of ADHD (ADHDct) and having one or more full siblings available for the ascertainment of clinical information and without a diagnosis of ADHD. This restricted the analysis to 1401 cases with diagnostic information. Symptom ratings were available for these cases and 1828 siblings. The families constitute a subsample of those who were recruited for the International Multi-Center ADHD Genetics Study (IMAGE: Faraone et al., 2005a) from 12 specialist clinics in Belgium, Germany, Holland, Ireland, Israel, Spain, Switzerland and United Kingdom. At all 12 centers an agreed study protocol in accord with the criteria of the Declaration of Helsinki was reviewed and approved by the local institutional review board. Verbal and written information was prepared for the children and the parents who provided written consent.

All children were aged from 5 to 17 years (cases: mean 10.9 years, SD 2.8; 
siblings: mean 10.9 years, SD 3.4), and were of European Caucasian descent. They had an IQ of $>70$ (cases mean 100.1, SD 15.7; siblings: mean 101.8, SD 14.3) on the short version of the WISC (information, picture arrangement, similarities and block-design: Sattler, 1992). Among the cases $86.5 \%$ and among the siblings $50.2 \%$ were male. Exclusion criteria for both cases and siblings included autism, epilepsy, general learning difficulties, brain disorders and any genetic or medical disorder associated with externalizing behavior that mimics ADHD. Table 2 shows the characteristics of the sample (gender, age, $I Q$, and socio-economic status).

\section{Table 2:}

Characteristics of the sample (percentages and standard deviations in parentheses)

\begin{tabular}{|c|c|c|c|c|c|c|}
\hline Group & Subgroup & $\mathrm{N}$ & $\begin{array}{l}\text { Age } \\
\text { (Years) }\end{array}$ & IQ & $\begin{array}{l}\text { Gender } \\
\text { (Males) }\end{array}$ & $\begin{array}{c}\text { Socio-economic } \\
\text { Scale (SES }\end{array}$ \\
\hline ADHD & ADHDonly & $\begin{array}{l}241 \\
\qquad(17.2 \%)\end{array}$ & $\begin{array}{l}10.8 \\
(2.7)\end{array}$ & $\begin{array}{l}101.5 \\
(15.3)\end{array}$ & $\begin{array}{l}204 * \\
\quad(84.6 \%)\end{array}$ & $\begin{array}{l}3.8 \\
(1.0)\end{array}$ \\
\hline \multirow[t]{4}{*}{$\mathrm{N}=1401^{\#}$} & ADHD+ODD & 202 & $\begin{array}{l}10.8 \\
(2.4)\end{array}$ & $\begin{array}{l}102.5 \\
\quad(16.4)\end{array}$ & $\begin{array}{l}175 * \\
(86.6 \%)\end{array}$ & $\begin{array}{l}3.9 \\
(1.0)\end{array}$ \\
\hline & $\mathrm{ADHD}+\mathrm{CD}$ & 11 & $\begin{array}{l}13.0 \\
(3.2)\end{array}$ & $\begin{array}{l}103.8 \\
(17.1)\end{array}$ & $\begin{array}{l}11 * \\
\quad(100 \%)\end{array}$ & $\begin{array}{l}4.2 \\
(0.7)\end{array}$ \\
\hline & $\begin{array}{l}\text { ADHD+ } \\
\text { ODD+CD }\end{array}$ & $\begin{array}{l}44 \\
(3.1 \%)\end{array}$ & $\begin{array}{l}10.2 \\
(2.8)\end{array}$ & $\begin{array}{l}99.0 \\
\quad(16.4)\end{array}$ & $\begin{array}{l}40 * \\
\quad(90.9 \%)\end{array}$ & $\begin{array}{l}3.7 \\
\quad(1.1)\end{array}$ \\
\hline & $\mathrm{ADHD}+\mathrm{CP}$ & $\begin{array}{l}768 \\
\quad(54.8 \%)\end{array}$ & $\begin{array}{l}11.0 \\
(2.8)\end{array}$ & $\begin{array}{l}98.6 \\
\quad(15.5)\end{array}$ & $\begin{array}{l}671 * \\
\quad(87.3 \%)\end{array}$ & $\begin{array}{l}3.7 \\
(1.1)\end{array}$ \\
\hline Siblings & No disorder & $\begin{array}{l}1123 \\
(61.4 \%)\end{array}$ & $\begin{array}{l}10.8 \\
(3.4)\end{array}$ & $\begin{array}{l}102.8 \\
(13.7)\end{array}$ & $\begin{array}{l}522 \\
(46.4 \%)\end{array}$ & $\begin{array}{l}3.5 \\
(1.3)\end{array}$ \\
\hline \multirow[t]{3}{*}{$\mathrm{N}=1828^{\#}$} & ADHDonly & $\begin{array}{l}252 \\
\quad(13.8 \%)\end{array}$ & $\begin{array}{l}10.7 \\
\quad(3.1)\end{array}$ & $\begin{array}{l}101.1 \\
\quad(15.0)\end{array}$ & $\begin{array}{l}136 \\
(53.9 \%)\end{array}$ & $\begin{array}{l}3.9 \\
(1.0)\end{array}$ \\
\hline & $\mathrm{ADHD}+\mathrm{CP}$ & $\begin{array}{l}233 \\
\quad(12.7 \%)\end{array}$ & $\begin{array}{l}10.6 \\
(3.2)\end{array}$ & $\begin{array}{l}96.7 \\
\qquad(15.3)\end{array}$ & $\begin{array}{l}142 * \\
(60.9 \%)\end{array}$ & $\begin{array}{l}3.4 \\
(1.0)\end{array}$ \\
\hline & CPonly & $\begin{array}{l}49 \\
(2.7 \%)\end{array}$ & $\begin{array}{l}10.6 \\
(3.0)\end{array}$ & $\begin{array}{l}103.6 \\
\quad(13.8)\end{array}$ & $\begin{array}{l}36 * \\
\quad(73.4 \%)\end{array}$ & $\begin{array}{l}\text { data missing } \\
\text { on } 48 \text { subjects }\end{array}$ \\
\hline
\end{tabular}

There were no group differences except for gender* where there were predominantly more males (MANOVA: $\mathrm{p}<.0001) .{ }^{\#}$ From the original sample data were missing for 135 cases $(9.6 \%)$ and 171 siblings $(9.4 \%)$.

\section{Clinical Measures}

Diagnoses were based on a standardized, semi-structured interview with the parents (Parental Account of Childhood Symptoms, [PACS]; Chen and Taylor, 2006; Taylor et al., 1991). Interviewers, who had received formal training in London, obtained detailed descriptions of the child's typical behavior in a range of specified situations defined by the context (e.g. play) or the behavior shown (e.g. crying). Items that had occurred in the previous week and in 
the previous year were rated on a 4-point scale for frequency and severity. PACS includes 4 subscales: hyperactivity (attention span, restlessness, fidgetiness and restlessness), defiance (e.g. tantrums, disobedience and destructiveness), emotionality (e.g. misery, worries, fears) and comorbid disorders (autistic spectrum, attachment, mania, substance-abuse, psychotic symptoms, obsessive-compulsive symptoms, and other specific developmental and neurological conditions). An age adjustment for symptom thresholds is built into the PACS algorithm for diagnosis. Situational pervasiveness is captured by the different situations investigated within the PACS interview as well as the presence of at least one symptom in each domain reported by teachers using the Conners CTRS ADHD sub-scales (see below).

Inter-rater reliability was high with product-moment correlations for pairs of interviewers ranging from 0.79 to 0.96 . A mean kappa coefficient across all the sites of 0.88 (range $0.71-1.00$ ) and an average agreement percentage of $96.6 \%$ (range 78.6-100) were obtained. Concurrent validity of PACS diagnosis was confirmed by the biserial correlation between PACS diagnosis of ADHDct with Conners Teacher $\mathrm{N}$-scale (18 DSM-items) scores at 0.68 and with Conners' Parent $\mathrm{N}$-scale scores at 0.78 .

ADHD symptoms in both cases and siblings were rated with the long version of Conners' parent and teacher rating scales (CPRS-R:L; CTRS-R:L (Conners, 2002), and the parent and teacher versions of the Strengths and Difficulties Questionnaires (SDQ: (Goodman, 1997; Woerner et al., 2004). The SDQ has 25 items on 5 scales relating to emotionality, conduct, hyperactivity/inattention, peer-problems, and pro-social behavior. The $\mathrm{N}$-scale of the CPRS and CTRS combines 18 items, compatible with the DSM-IV checklist, from 9 inattentive (subscale L) and 9 hyper- active-impulsive items (subscale $\mathrm{M}$ ). Missing subscale data were prorated if 7 or more from 9 items were present. T-scores (standardized for age and gender) for the CPRS and CTRS were based on published data (Conners, 2002), and for the SDQ a comparable procedure was based on tables from R. Goodman (personal communication).

As PACS information was not available for all siblings, the CP/TRS and SDQ ratings were used to define the "presence" of ADHD and CP symptoms in these children who otherwise had no diagnosis. ADHD was recorded as present for a T-score of $\geq$ 65 (1.5 standard deviations over the mean) on the CPRS and CTRS 18 item DSM-IV scales. Concurrent validity for Conners and clinical assessments have been reported (Conners et al., 1998a; Conners et al., 1998b; Kuntsi and Stevenson, 2001). The ADHD criterion was shown by 485 siblings. $\mathrm{CP}$ was recorded as present on the basis of conduct items from CPRS and CTRS oppositional subscales and the SDQ conduct scale in all children. The SDQ items (rated 0-2) concern temper tantrums, obedience, arguing a lot, lying and stealing, and the CP/TRS items (rated 0-3) include anger-resentment, fighting or arguing with adults, loss of temper, irritability, defiant or not compliant with adult requests, easily annoyed, blaming others for own misbehavior, intentional annoyance of others and spiteful-vindictive behavior.

To exclude autism spectrum disorders that might confound the analysis of ADHD, both cases and siblings were screened using the Social Communication Questionnaire $(\geq 15)$ in conjunction with the pro-social scale from the SDQ $(\leq 4)$. Those falling outside these thresholds were further evaluated with the autism spectrum disorder section of the PACS interview.

\section{Statistical Analyses}

All raw data were stored on a database at 
the London site with the ratings controlled for consistency by entry and re-entry of the data at two time points. Data reduction and analyses were carried out using the statistical package STATA version 9 and SPSS 14.0.

As PACS data were not available for all siblings we evaluated initially the concurrent validity of the CP/TRS and SDQ oppositional scales against the PACS diagnosis of CD/ODD found in the cases to reduce the likelihood of misclassification. First, point-serial correlations (after Pearson) were computed between the ODD/CD PACS status and the CP/TRS and SDQ scales. Second, linear discriminant analyses were used to assess which scales (or combination of scales) provided the best prediction of ODD/CD cases. The sensitivity and specificity of the composite construct of conduct problems (CP) against the PACS diagnoses was calculated. Lastly receiver operating characteristics (ROC) were plotted to show the rate of the true positive rate against the false positive one for the chosen scales.

In the second stage of the main analysis, a multinomial logistic regression to ascertain the pattern of recurrence risks of ADHD and comorbid conditions amongst siblings was used. More specifically, we tested whether there was a specific pattern in the siblings' recurrence risks as predicted by the status of the cases as ADHDonly or $\mathrm{ADHD}+\mathrm{CP}$ consistent with cosegregation. Thus all cases were used as predictors (independent variables) and all siblings as criterion (dependent variables). As the predictions above are based on related groups (the cases and their siblings are statistically not independent), we applied Huber's bootstrap corrections, as implemented in STATA to correct for correlated family data (see Faraone et al., 2000b).

In a last step, MANOVAS were calculated to assess the severity of symptoms for the different subgroups (i.e. ADHDonly, $A D H D+C P$, and for siblings additionally CPonly, and no disorder). CPRS and CTRS ratings of the DSM-IV based ADHDct were entered into the MANOVA as measures of symptom severity. Analyses were repeated for both cases and siblings younger and older than 11 years, in order to see if the prevalence of the comorbid condition increased with age or remained stable. The choice of 11 years reflects the median onset age of $11.6 y$ reported by Nock et al. (2006), who also described an agedependent increase of CD prevalence.

\section{Table 3:}

Correlations for Conners and SDQ Parent and Teacher Rating-Scales with PACS assessments of ADHD, with/without ODD and CD

\begin{tabular}{lcccc}
\hline $\begin{array}{l}\text { ADHD } \\
\text { Groups }\end{array}$ & $\begin{array}{l}\text { Conners Parent } \\
\text { Oppositional }\end{array}$ & $\begin{array}{l}\text { Conners Teacher } \\
\text { Oppositional }\end{array}$ & $\begin{array}{c}\text { SDQ Parent } \\
\text { Conduct Problems }\end{array}$ & $\begin{array}{c}\text { SDQ Teacher } \\
\text { Conduct Problems }\end{array}$ \\
\hline $\begin{array}{c}\text { ADHDonly } \\
(\mathrm{n}=1009 *)\end{array}$ & -.454 & -.117 & -.420 & -.183 \\
$+\underset{(\mathrm{ODD}}{(\mathrm{n}=202)}$ & +.448 & +.117 & +.407 & +.182 \\
$+\underset{(\mathrm{n}=11)}{\mathrm{CD}}$ & +.331 & +.115 & +.424 & +.171 \\
$+\underset{(\mathrm{ODD}+\mathrm{CD}}{(\mathrm{n}=44)}$ & +.345 & +.114 & & +.418 \\
\hline
\end{tabular}

All positive and negative correlations were significant (Point serial correlations after Pearson, two-way $\mathrm{p}<.0001)$. Cases were defined from PACS assessments) 


\section{Results}

\section{Psychometric validity of rating scales}

Correlation coefficients were calculated to show the degree of concordance between different informants (teacher, parent) on the CPRS-R: L, CTRS-R: L, SDQ (and their oppositional or CP subscales), and PACS ratings for $O D D$ and $C D$ for cases only (table 3).

There were strong correlations for both sets of parental ratings with the diagnostic assessments of ODD and CD from the PACS. The correlations for teacher ratings were weaker yet remained highly significant. Importantly, the ODD and CD diagnoses derived from PACS diagnoses of cases correlated positively with parent and teacher ratings on the Conners and SDQ oppositional scales, whereas the group of cases with ADHDonly defined by PACS showed negative correlations with the CP. Thus, concurrent validity for CP items is apparent.

To examine further potential informant effects, parent and teacher ratings of oppositional behavior or putative $\mathrm{CP}$, as measured by the Conners and SDQ scales, were entered into a stepwise linear discriminant analysis (LDA). Parents' ratings of $\mathrm{CP}$ items on the CPRS and SDQ oppositional scales yielded the best discrimination of ADHDonly, CD, ODD groups defined by PACS. They correctly classified $70.4 \%$ of all cases; $69.6 \%$ of cases with ADHDonly (specificity) and $73.2 \%$ of cases with ADHD+ODD+CD (sensitivity).

\section{Table 4:}

Results of the multinomial linear regression predicting presence/absence of ADHD, ADHD+CP or CP status in siblings from the status of combined type ADHD cases with or without CP.

\begin{tabular}{|c|c|c|c|c|c|}
\hline \multirow[t]{2}{*}{ Case Status } & \multicolumn{3}{|c|}{ Sibling Status } & & \multirow[t]{2}{*}{ Total } \\
\hline & No Disorder & ADHDonly & $\mathrm{ADHD}+\mathrm{CP}$ & CPonly & \\
\hline $\begin{array}{l}\text { ADHDonly } \\
\left(241^{*}\right)\end{array}$ & $\begin{array}{l}230 \\
86.1 \%\end{array}$ & $\begin{array}{l}20 \\
7.5 \%\end{array}$ & $\begin{array}{l}13 \\
4.9 \%\end{array}$ & $\begin{array}{l}4 \\
1.5 \%\end{array}$ & 267 \\
\hline $\begin{array}{c}\mathrm{ADHD}+\mathrm{CP} \\
(768)\end{array}$ & $\begin{array}{l}848 \\
64.1 \%\end{array}$ & $\begin{array}{l}216 \\
16.3 \%\end{array}$ & $\begin{array}{l}215 \\
16.2 \%\end{array}$ & $\begin{array}{l}45 \\
3.4 \%\end{array}$ & 1324 \\
\hline \multicolumn{6}{|c|}{$\underline{\text { Relative Risk Ratio }}{ }^{1}$} \\
\hline$(95 \% C I)$ & & $\begin{aligned} 2.93, \mathrm{p} & <.001 \\
& (1.7-5.0)\end{aligned}$ & $\begin{aligned} 4.49, \mathrm{p} & <.001 \\
& (2.6-7.8)\end{aligned}$ & $\begin{array}{r}3.05, \mathrm{p}<.034 \\
(1.1-8.5)\end{array}$ & \\
\hline $\begin{array}{l}\frac{\text { Adjusted Re }}{\text { Risk Ratio }}{ }^{2} \\
(95 \% \text { CI })\end{array}$ & & $\begin{aligned} 2.92, \mathrm{p} & <.001 \\
& (1.6-5.3)\end{aligned}$ & $\begin{aligned} 4.93, \mathrm{p} & <.001 \\
& (2.6-9.4)\end{aligned}$ & $\begin{array}{l}5.67, \mathrm{p}=.019 \\
\quad(1.3-24.2)\end{array}$ & \\
\hline Total & $\begin{array}{l}1078 \\
67.8 \%\end{array}$ & $\begin{array}{l}236 \\
14.8 \%\end{array}$ & $\begin{array}{l}228 \\
14.3 \%\end{array}$ & $\begin{array}{l}49 \\
3.1 \%\end{array}$ & $\begin{array}{l}1591 \\
100 \%\end{array}$ \\
\hline
\end{tabular}

Pearson's Wald Chi ${ }^{2}(9)=49.55, \operatorname{Pr}<.001$

1. Relative Risk Ratio (RRR) is computed as the ratio of risk in siblings of ADHDonly cases (as the comparison group) to those of ADHD+CP cases.

2. Data adjusted for gender and parental socio-economic status (SES)

* sample numbers are based on PACS diagnosis of ADHD with (ADHDonly) and without (ADHD+CP) CP scores based on CPRS and SDQ ratings. 
Lastly, ROC-curves for the parental ratings on both the Conners and SDQ oppositional subscales and for the combined CP scale were plotted (Fig. 1). The closer the curve follows the left-hand border and the larger the area under the curve, the better is the prediction. The closer the curve comes to the 45-degree diagonal of the ROC space, the less accurate is the prediction. Each ROC-curve in figure $1 \mathrm{a}$ and $1 \mathrm{~b}$ followed the left-hand and then the top border, and thus showed a high accuracy for the scales. The areas under both curves (SDQ and CPRS ratings) indicated a high degree of correspondence between the CP construct and DSM-IV CD diagnosis (.84 and .86 respectively) as did the combined CP-Scale (.86). Thus, the findings confirmed with three different analyses that the composite of parent SDQ conduct and Conners' oppositional items is a sensitive and specific measure for differentiating between individuals with and without CP.

To reduce the potential for misclassification of siblings further, the ROC-curve was used to identify the best cut-off point for identifying $C P$. The findings show CP was best defined by a composite of the CPRS and SDQ subscales scoring $T=65$ and more on the CPRS (1.5 standard deviations above a mean of 50 ) and scoring $\geq 4$ on the SDQ Parent conduct

\section{Figure 1:}
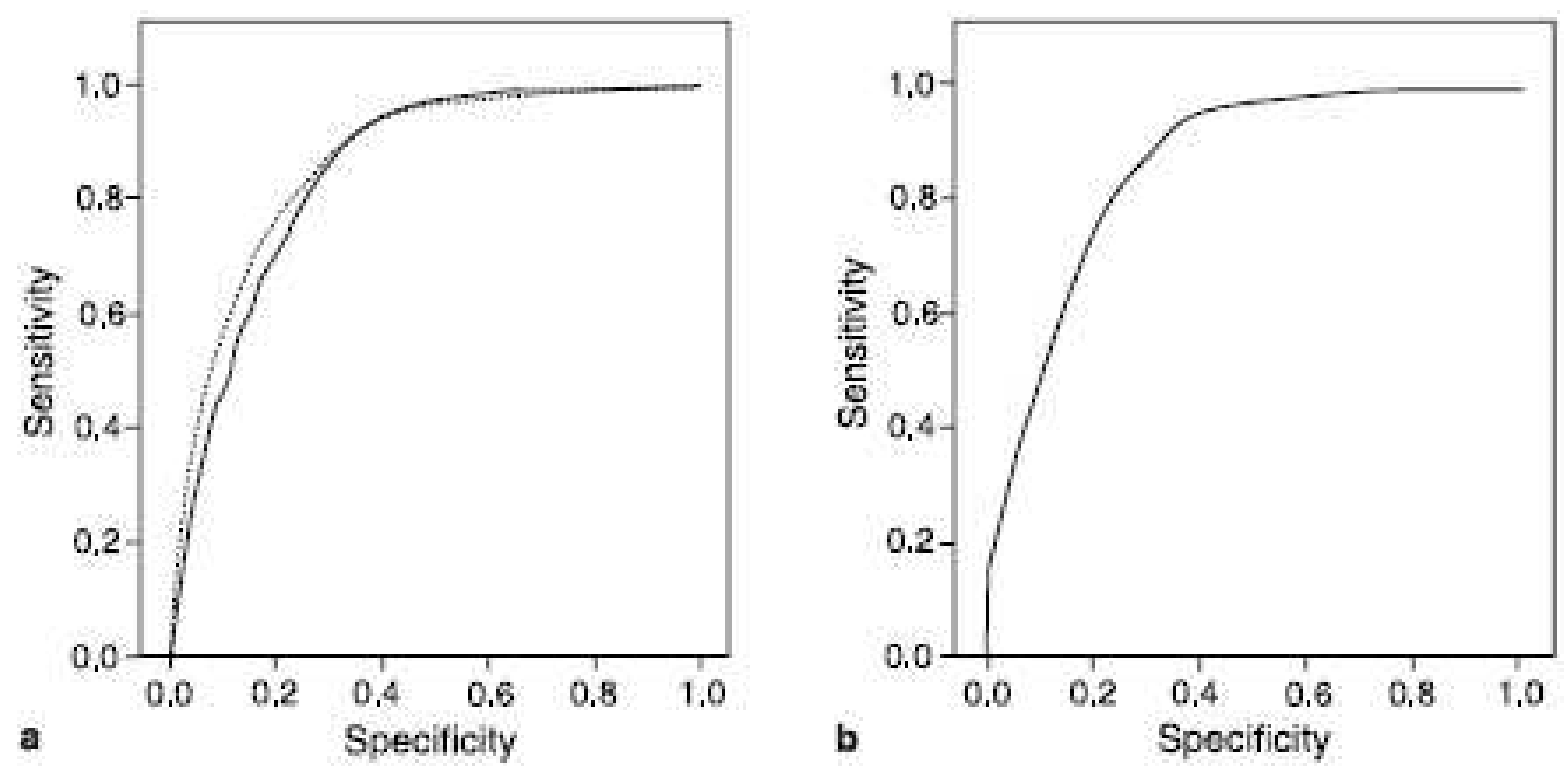

Figure 1a:

Receiver operating characteristic (ROC)-curves and areas under the curve for parental ratings of oppositional behavior based on Conners and SDQ scales: The area under the curve for the CPRS oppositional scale is .847 and for the parent SDQ is .865 .

\section{Figure 1b:}

The ROC curve for the combined parental ratings of oppositional behavior (CP): the area under the curve is .860 . 
scale. This corresponds to a cut-off above the $85^{\text {th }}$ percentile in both rating scales. This analysis was based on data derived from 498 cases with available PACS and rating scale data. Thus all further analyses of $C P$ in ADHD cases and siblings relied on this combination of measures for identifying $\mathrm{CP}$ and resulted in the identification of 768 cases and 282 siblings with CP.

\section{Patterns of familial co-transmission}

A multinomial logistic regression (MLR) was conducted to test the hypotheses in table 1 by ascertaining the siblings recurrence risks for 'no disorder', 'ADHDonly', 'CP-only' and 'ADHD+CP' subgroups (table 4). This prediction of the pattern of symptoms recorded in the siblings was based on using cases with ADHDonly and ADHD+CP as independent variables, and subgroup membership for the siblings as the dependent variable. (The regression was confined to this comparison as the IMAGE sample did not include an unrelated control group without diagnoses of ADHD or ratings of $\mathrm{CP}$. To control for the relationship between groups, Huber's correction was applied.)

Table 4 illustrates the pattern of cotransmission of 'ADHD+CP'. Based on 267 siblings of 241 cases with ADHDonly, 4.9\% of the siblings were rated as showing ADHD+CP symptoms. This proportion increased by $11.4 \%$ on examination of 1324 siblings of 768 cases with ADHD+CP. Comparing these ratios, the relative risk for concordance was 4.5 , and rose to 4.9 after taking socio-economic status and gender into consideration (see table 1, proposal 2). However, the relative risk for a discordant status in siblings (ADHDonly) of cases with $A D H D+C P$ also rose significantly, albeit to a lesser extent (6.2\%: see proposal 3). The prevalence of CPonly in siblings of cases with $A D H D+C P$ also rose significantly (by $1.9 \%$ ), but is less firmly based on the relatively few subjects in the analysis (see proposal 4).

\section{Severity of Symptoms}

We examined whether cases and siblings show more ADHD symptoms when $C P$ is also present, to see if $A D H D+C P$ may be considered as a more severe disorder than ADHDonly. Differences in ADHD severity across diagnostic subgroups were calculated from the means of the 18 DSMIV ADHDct symptom scores in the CP/TRS. They were entered into a MANOVA comparing all cases (ADHDonly, ADHD+CP) and all siblings (no disorder, ADHDonly, ADHD+CP, CPonly: see table 5).

The ADHD+CP subgroup showed the more severe symptom scores in both parent and teacher ratings, for both cases and siblings. The siblings with no disorder or CPonly were the least disturbed. Multivariate tests were highly significant between groups (cases: ADHDonly vs. ADHD+CP; siblings: no disorder, ADHDonly, $A D H D+C P$, CPonly) with effect sizes accounting for $11 \%$ and $45 \%$ of the differences, respectively.

\section{Age Comparisons}

Analyses were repeated for cases and siblings 11 years and younger and those over 11 years, in order to examine whether the distinct comorbid ADHD+CP subtype is stable across the age span studied, or if an increasing prevalence is a feature of increasing age. There were overall fewer children older than 11 years for cases and siblings.

As above, parent and teacher ratings for the Conners DSM-IV ADHDct scale were entered into a MANOVA (cases with ADHDonly, or $A D H D+C P$, and siblings with no disorder, ADHDonly, $A D H D+C P$, or CPonly). The ADHD+CP cases showed more symptoms overall across the age span (except for teacher ratings of younger ADHDonly cases), and the older cases showed more symptoms than the younger ones (table 6a). Both main effects (for age 
and $\mathrm{CP}$ ) were significant, but accounted for only $2 \%$ and $5 \%$ of the variance respectively. The interaction between age and $\mathrm{CP}$ was also significant, but accounted for only $0.5 \%$ of the variance.

A similar pattern emerged for the siblings (table 6b). Siblings with ADHD+CP showed more symptoms in both parent and teacher ratings than the other conditions, regardless of age. Further, the symptom ratings were more severe for children older than 11 years. Both main effects (age and disorder) were significant, accounting for $1 \%$ and $43 \%$ of the variance respectively. The interaction (age $x$ disorder) was small ( $1 \%$ explained variance), but significant.

\section{Table 5:}

MANOVA comparing ratings of severity (T-scores) on the Conners' scales in subgroups of cases and siblings (means and standard deviations)

\begin{tabular}{|c|c|c|c|c|c|c|c|}
\hline \multirow{2}{*}{\multicolumn{2}{|c|}{$\begin{array}{l}\text { DSM-IV } \\
\text { Combined Type } \\
\text { (Conners' ratings) }\end{array}$}} & \multicolumn{2}{|c|}{ Cases } & \multicolumn{4}{|c|}{ Siblings } \\
\hline & & \multirow{2}{*}{$\begin{array}{r}\text { ADHD } \\
\text { only }\end{array}$} & \multirow{2}{*}{$\begin{array}{c}\begin{array}{c}\text { ADHD } \\
+ \text { CP }\end{array} \\
\begin{array}{c}79.8 \\
8.9\end{array}\end{array}$} & \multirow{2}{*}{$\begin{array}{l}\text { No disorder } \\
\\
66.8 \\
6.8\end{array}$} & \multirow{2}{*}{$\begin{array}{c}\begin{array}{r}\text { ADHD } \\
\text { only }\end{array} \\
\begin{array}{c}69.0 \\
9.8\end{array}\end{array}$} & \multirow{2}{*}{$\begin{array}{c}\text { ADHD } \\
+ \text { CP }\end{array}$} & \multirow{2}{*}{$\begin{array}{l}\mathrm{CP} \\
\text { only } \\
54.9 \\
5.5\end{array}$} \\
\hline Parent & $\begin{array}{l}\text { mean } \\
S D\end{array}$ & & & & & & \\
\hline Teacher & $\begin{array}{l}\text { mean } \\
S D\end{array}$ & $\begin{array}{r}68.9 \\
10.5\end{array}$ & $\begin{array}{l}70.0 \\
\quad 12.2\end{array}$ & $\begin{array}{l}52.0 \\
11.9\end{array}$ & $\begin{array}{l}61.4 \\
12.8\end{array}$ & $\begin{array}{l}65.0 \\
\quad 14.3\end{array}$ & $\begin{array}{r}56.2 \\
11.5\end{array}$ \\
\hline$\underline{\text { Multivari }}$ & $\begin{array}{l}\text { Wilks I } \\
\text { F } \\
\text { df } \\
P \\
\eta^{2}\end{array}$ & $\begin{array}{l}1 \\
3 \\
.0 \\
.1\end{array}$ & & & .0 & & \\
\hline
\end{tabular}

T scores of $>70$ are $2 \mathrm{SD}$ above the mean of 50

\section{Discussion}

There are two key findings in this study. First, in a family with a case of ADHDct with conduct problems (ADHD+CP) there was a nearly 5 -fold increased risk of the sibling showing $A D H D+C P$ over the likelihood of this status if the case was diagnosed with ADHDct only. The recurrence of the risk for $A D H D+C P$ in siblings suggests that $A D H D+C P$ often has a prevalence consistent with co-segregation and may thus often constitute a distinct familial disorder (proposal 2, table 1). However, the evidence also suggests that this is not always so. The second finding shows that, if cases have CP along with a diagnosis of ADHD, then there is a nearly 3fold increased likelihood that the ADHD part of their disturbance will also be shown by their siblings. This supports the widely reported high heritability for ADHD, and perhaps a genetic contribution to the etiology of ADHD (proposal 3). The implication is that the ADHD+CP condition represents a more severe disturbance than ADHD alone.

Indeed, this ADHD+CP subtype manifested more severe symptoms of ADHD than those classified as having ADHDonly or CPonly. This characteristic is detected in both younger and older subjects, with a tendency towards a more 


\section{Table 6:}

A) MANOVA comparing Conners' severity ratings (T-scores: DSM-IV ADHD combined type) for younger $(\leq 11 \mathrm{y})$ and older subjects $(>11 \mathrm{y})$ in ADHDonly and ADHD+CP cases.

B) MANOVA comparing Conners' severity ratings (T-scores: DSM-IV ADHD combined type) for younger $(\leq 11 \mathrm{y})$ and older subjects $(>11 \mathrm{y})$ in 4 groups of siblings (No disorder, ADHDonly, ADHD+CP, CPonly).

\begin{tabular}{|c|c|c|c|c|c|}
\hline A/ Cases & & Conners (parent) & $\frac{\mathbf{l y})}{\text { nners (teacher) }}$ & Conners (parent) & $\frac{1 \mathbf{y})}{\text { nners (teacher) }}$ \\
\hline ADHDonly & Mean / SD & $72.1 / 9.4$ & $68.5 / 9.2$ & $72.2 / 13.3$ & $69.4 / 12.4$ \\
\hline $\mathrm{ADHD}+\mathrm{CP}$ & Mean / SD & $78.2 / 8.5$ & $67.2 / 11.0$ & $82.0 / 9.1$ & $72.9 / 12.8$ \\
\hline $\begin{array}{l}\text { Main effects } \\
\text { Interaction }\end{array}$ & $\begin{array}{l}\text { Age } \\
+/-\mathrm{CP}\end{array}$ & $\begin{array}{l}\mathrm{F} \\
14.2 \\
37.8 \\
3.5\end{array}$ & $\begin{array}{l}\mathrm{df} \\
2.0 \\
4.0 \\
4.0\end{array}$ & $\begin{array}{l}\mathrm{p} \\
.0001 \\
.0001 \\
.008\end{array}$ & $\begin{array}{l}\eta^{2} \\
.021 \\
.054 \\
.005\end{array}$ \\
\hline
\end{tabular}

B/ Siblings

younger $\underline{(\leq \mathbf{1 1 y})}$

older $\frac{(>11 y)}{\operatorname{conn}}$

Conners (parent) Conners (teacher) Conners (parent) Conners (teacher)

\begin{tabular}{|c|c|c|c|c|c|}
\hline No Disorder & Mean / SD & $47.4 / 5.8$ & $51.0 / 9.6$ & $45.9 / 7.9$ & $53.4 / 14.4$ \\
\hline ADHDonly & Mean / SD & $67.5 / 9.7$ & $59.9 / 10.8$ & $71.2 / 9.5$ & $63.6 / 15.1$ \\
\hline $\mathrm{ADHD}+\mathrm{CP}$ & Mean / SD & $76.3 / 8.9$ & $62.8 / 13.8$ & $78.1 / 9.6$ & $68.4 / 14.4$ \\
\hline CPonly & Mean $/ S D$ & $55.5 / 5.3$ & $54.6 / 11.4$ & $54.1 / 5.7$ & $58.2 / 11.7$ \\
\hline \multirow[t]{3}{*}{$\underline{\text { Main effects }}$} & & $\mathrm{F}$ & $\mathrm{df}$ & $\mathrm{p}$ & $\eta^{2}$ \\
\hline & Age & 9.4 & 2.0 & .0001 & .011 \\
\hline & Disorder & 321.1 & 8.0 & .0001 & .438 \\
\hline Interaction & & 4.4 & 8.0 & .0001 & .011 \\
\hline
\end{tabular}

marked expression in adolescents than in children. In other words, this feature of severity supports the distinction of $A D H D+C P$ from other subtypes in both the younger and the older individuals. Thus, there is familial, and a certain degree of predictive validity for $A D H D+C P$ as a distinct subtype.

The strength of these results is emphasized by the demonstration of the validity of the definition of $C P$ based on parent and teacher ratings on two symptom assessment scales (Conners' scales and the SDQ) against the diagnosis of comorbid ODD and CD in ADHD cases resulting from the PACS.
However, there was a third less robust finding. There were comparatively few siblings of $A D H D+C P$ cases who showed CPonly. Nonetheless there was an increased risk of siblings showing CPonly if the cases had $A D H D+C P$ rather than ADHDonly. The increased perception of $C P$ in these siblings tentatively points to shared common risk factors that were likely to be of an environmental nature (proposal 4). But, two features may be considered as potentially influencing this and the main result above. First, the parent's perception and ratings of $\mathrm{CP}$ in the siblings may be 'sensitized' by the severity of the ADHD+CP status of the case in the family. Second, this feature could be 
compounded by the number of families in which there were several siblings of the ADHD+CP case.

\section{Psychometric validity}

The CP construct used here has been validated against $C D$ and ODD diagnostic categories based on PACS, a research diagnostic instrument. Biserial correlations confirmed strong associations between PACS ratings of $O D D / C D$ and the oppositional rating scales used. Correlations also showed the expected concurrent and discriminant validity, as indicated by positive correlations for cases with ODD/CD and negative ones for cases with ADHDonly. Discriminant analyses identified parental oppositional ratings for SDQ and CPRS as the best predictors of cases with and without ODD/CD according to PACS. Teacher ratings showed lower correlations and did not contribute as much to the discrimination of groups as the parent ratings. ROC-curves confirmed the high accuracy for both parental measures. Thus the psychometric properties of the $\mathrm{CP}$ construct defined here have been robustly tested and validated.

Support for the proposals and consistency with other findings

The findings help to reconcile in part the previously divergent research findings reported by family studies (Faraone et al., 1991; Faraone and Biederman, 1997; Faraone et al., 2000a) and twin studies (Thapar et al., 2001; Vierikko et al., 2004). Both directions receive some support. Findings from family studies (Faraone et al., 1991; Faraone and Biederman, 1997; Faraone et al., 2000) largely support the co-segregation of $\mathrm{ADHD}+\mathrm{CP}$ amongst relatives, and that this subtype is a distinct familial condition (proposal 2). Twin studies (Thapar et al., 2001; Vierikko et al., 2004) on the other hand support the model that $A D H D$ and $C P$ share common underlying genetic and environmental influences; and that the ADHD+CP subtype merely represents a severe variant of a continuous ADHD trait with a corresponding genetic loading (proposal 3). It is therefore not a distinct disorder. We show an increased risk for both etiologies, although the relative risk for the former is much higher.

Certainly, 'ADHD+CP' is often a distinct familial disorder characterized by severe symptoms that maintain the differentiation from other groups across the 5-17 year age-span studied. There is familial, concurrent and predictive validity in the postulate of 'ADHD+CP' being a distinct condition The findings therefore combine and reconcile proposals 2 and 3 in so far as: $A D H D+C P$ can be a distinct familial subtype, and is then characterized by more severe ADHD symptoms. Similarly in a recent study of 457 adolescents with and without ADHD, Hurtig et al. (2007) reported that those with comorbid $C D$ and ODD showed more ADHD symptoms than others with ADHDonly. Our finding milder and more severe variants of ADHDct cases concurs with others from Latent Class Analyses, which have consistently identified distinctive 'moderate-ADHDct' and 'severe-ADHDct' subtypes across twin samples in the USA, (Todd et al., 2002), Brazil (Rohde et al., 2001) and Australia (Rasmussen et al., 2002). However, Latent Class Analysis has not so far identified severe-ADHDct associated with ODD or CD (Volk et al., 2006), although the canonical correlation analysis by Mathias et al. (2007) described an association of impulsive-conduct problems with inattentive and hyperactive components of ADHD and that impulsivity was the common construct underlying ADHD and CD.

Overall, cases and siblings with $A D H D+C P$ showed more severe hyperactivity, impulsivity, and inattention on the Conners DSM-IV ADHDct scale (both parent and teacher ratings) compared to those with ADHDonly, CPonly, or no 
disorder. The severity of these symptoms increased in cases and siblings older than 11 years of age compared to the younger participants. These results are in accord with Nock et al. (2006) who also reported more severe symptoms for children with ADHD and CD who were older than 11 years. These findings thus also agree with studies proposing that $A D H D+C P$ is a more severe disorder, distinct from ADHDonly (Thapar et al., 2001, Faraone et al., 1991, Faraone et al., 1997, Faraone et al., 2000a). Recently this could also be shown for adults with ADHD with and without ODD (Gadow et al., 2007).

Against our predictions, our findings offer some support for the DSM-IV nosological paradigm that $A D H D+C P$ represents an over-lap of two independent conditions for $A D H D$ and $C P$. But this overlap would be more embodied in proposal 4, which emphasizes shared environmental risk factors, than in proposal 1 that suggests co-occurrence by chance. But the findings are based on too few subjects to test reliably the shared 'toxic environment' hypothesis (exemplified by proposal 4: Taylor et al., 1991; Drabick et al., 2006). However, the implication is that a shared exposure to the same pathogenic features of the environment could be a contributor in some instances, for there were increased rates of all 3 disturbances assessed in the siblings of cases with ADHD+CP.

Levy et al. (2006) identified heterogeneity of $C D$ in their Australian twin study. Their analysis decomposed CD into three categories: that is, those expressing mild, moderate and severe symptoms (see introduction). On their ACE analysis severe $C D$ had a very high common environment factor, and a negligible effect of heritability: (i.e. growing-up in the same family has a strong influence on the development of extreme $C D$, but far less on the appearance of ADHD or milder forms of $C D$ ). Further, extreme $C D$ (compared to mild or moderate CD) was much less correlated with the expression of the main domains of ADHD and seemed distinct from mild and moderate CD. Importantly, they reported that milder conduct problems (CP) are more likely to be comorbid with ADHD (and have a common biological etiology). This scheme is broadly compatible with the present results. The construct of $A D H D+C P$ bears resemblance to the milder form of $C D$ defined by Levy et al. and is here more closely associated with ADHD. However, the present data do not allow a meaningful analysis of variants of $\mathrm{CP}$ stratified by severity.

Molecular genetic studies have started to identify contributions to a potential genetic etiology of ADHD+CP as implicated by specific risk alleles associated with the comorbid variant. Kirley et al. (2004) observed significant association between DRD4 7-repeat allele transmission and ADHD children with comorbid ODD. The DRD4 7-repeat allele was also significantly associated with positive family history of ADHD. Rowe et al. (1998) found that paternal DRD4 7-repeat risk allele was closely associated with the ADHD and conduct symptoms, while the maternal DAT1 10/10 repeat risk allele associated with inattention symptoms (Kirley et al., 2004; Rowe et al., 1998). Further genetic analyses of this nature are in progress with the IMAGE sample and will help elucidate the molecular basis for the risk of transmission.

\section{Limitations to the study}

There are a several limitations to this study. First, no independent healthy controls were recruited. Therefore statements of risk for $A D H D$ and $C P$ symptoms among siblings relate not to the population at large, but are relative between cases of ADHD with and without CP. Secondly, PACS data was not available 
for the all siblings. Original recruitment instructions required a sibling without a diagnosis of ADHD, and therefore PACS was ascertained only for persons where there were clinical reasons to doubt the absence of the condition. Thus, the classification of sibling groups could only be based on information derived from questionnaire data. However, validity and psychometric properties of the scales used have been well validated (e.g. Kunsti \& Stevenson, 2001; Goodman 1997; Woerner et al., 2004; Conners et al., 1998a). Thus misclassification due to false information is unlikely to provide a substantial bias to the results. It could be argued that the significant difference in size between the correlations for parent and teacher ratings with PACS assessments (table 3) undermines the reliability of the $\mathrm{CP}$ designation. However, we note first that correlations from both information sources were highly significant $(p<.0001)$, and second that correlations for parent Conners and SDQ ratings with PACS scores would likely be higher as parents were also the information source for the PACS assessments. Thirdly, this does not represent a meaningful bias as the correlations were highly significant between both the parent and teacher ratings of Conners' oppositional ( $r=.21$, $p<.01$, 2-tail) and those for SDQ oppositional features $(r=.33, p<.01)$.

The number of siblings in the logistic regression varied considerably and the procedure would have benefited from data from independent controls. However, as there were large numbers for the groups central to the analysis, the multivariate procedures used were adequate. Nevertheless, future studies should confirm our findings in larger and more balanced samples. In the current sample, male cases with ADHD outnumbered females, whereas the gender ratio was almost equal for siblings of cases. Since $A D H D$ and $A D H D+C P$ affect more boys than girls, the results on $A D H D+C P$ could also reflect a general gender bias. However, this seems unlikely for an increased representation of female siblings would not favor the high proportion of $A D H D+C P$ siblings recorded.

A developmental question arises over the predictive validity of $A D H D+C P$ as a distinct subtype. $C D$ itself does not necessarily persist in older cohorts. Longitudinal data will be needed to demonstrate conclusively if there is a similar pattern for $A D H D+C P$, and whether $A D H D$ and $C P$ are distinct components or multiple explanations are required for the developmental course of separate and combined phenocopies. Further, this issue overlaps with an increasing awareness of pleiotropic effects. We have already noted above that there may be a common genetic influence on hyperactivity and $\mathrm{CP}$ in a twin study (Silberg et al. 1996). Recently, Jain et al. (2007) provided evidence in a linkage analysis for a common inheritance pattern for the cosegregation of ADHD with disruptive behaviors. While such evidence for pleiotropy supports evidence presented here for a distinct $A D H D+C P$ subtype the role of maturation in the expression of a gene or of several genes will only be resolved with longitudinal data.

Lastly we should mention that a potential limit of the current study lies with the possibility for bias in the ascertainment of cases. The research protocol of the IMAGE project was strict and complex. The informed consent procedures required parents reading extensive written information. This may have incurred lower participation rates by families with social disadvantage and a higher problem burden, such as having children with ADHD and CP. Related to this, the requirement for the availability of the biological parents in the IMAGE study may also have reduced the proportion of 
families participating from disadvantaged backgrounds.

Thus future work should focus on ADHD and CD/ODD as defined by DSM-IV and ICD-10 with regard to the nature of recruitment and referral (Smith and Taylor, 2006), the environment in which the children are raised (e.g. rural vs. urban: Goodman and Stevenson, 1989), take account of the apparent gender differences that will also influence outcome (Kratzer \& Hodgins, 1997) and relate the results to an independent agematched control or comparison group.

\section{Conclusions}

The results support the frequent occurrence of $A D H D+C P$ as a distinct disorder, based on the nearly 5-fold increased risk of recurrence in siblings of the same "comorbid" disturbance compared to the appearance of ADHD+CP symptoms in siblings of cases with ADHDonly. However, a 2- to 3-fold increased relative risk for the ADHD or $C P$ components to appear separately in siblings of $A D H D+C P$ cases suggests both that $A D H D+C P$ can also be a more severe variant of the ADHDct diagnosis and that the environment can exert an influence on the development of the condition. These conclusions are supported by ratings of the increased severity of symptoms expressed in youngsters with $A D H D+C P$ compared to ADHDonly, and the relative stability of this expression, with symptoms becoming moderately more severe with age.

Nonetheless the evidence that for some families there is an increased risk of prevalence for ADHD in siblings of cases with ADHD+CP supports the DSM-IV view of the disturbances representing variants of a single disorder. In contrast, for other families the familial nature and predictive validity of $A D H D+C P$ support the maintenance of this entity in the ICD-10 category of hyperkinetic conduct disorder (F90.1). But, this ICD-10 category explicitly refers to $C D$, a more severe form of $C P$ and not ODD. In our and other studies $A D H D+C P$ resembles a slightly different category with the milder symptoms of $\mathrm{CP}$ more closely related to ODD. As neither DSM-IV nor ICD-10 recognizes this nosological entity, the placement of this category along the dimension of oppositional behavior remains a topic for further study

Reference List

Asherson P, Image Consortium (2004) Attention deficit hyperactivity disorder in the post-genomic era. Eur Child Adolesc Psychiat 13: 50-66

August GJ, Stewart MA (1983) Familial subtypes of childhood hyperactivity. J Nerv Ment Dis 171: 362-368

August GJ, Stewart MA, Holmes CS (1983) A four-year follow-up of hyperactive boys with and without conduct disorder. Br J Psychiat 143: 192-198

Banaschewski T, Brandeis D, Heinrich $H$, Albrecht B, Brunner $E$, Rothenberger A (2003) Association of ADHD and conduct disorder - brain electrical evidence for the existence of a distinct subtype. J Child Psychol Psychiat 44: 356-376

Burt SA, McGue M, Krueger RF, lacono WG (2005) Sources of co-variation among the child-externalizing disorders: informant effects and the shared environment. Psychol Med 35: 11331144

Chen W, Taylor EA (2006) Parental Account of Children's Symptoms (PACS), ADHD phenotypes and its application to molecular genetic studies. In: Oades RD (Ed) Attention-Deficit/Hyperactivity Disorder and the Hyperkinetic Syndrome: Current Ideas and Ways Forward. Hauppauge, NY 11788: Nova Science Publishing Inc, pp 3-20

Conners CK (2002) Manual for Conners' 
rating scales. N. Tonawanda, NY: MultiHealth Systems Inc

Conners CK, Sitarenios G, Parker JDA, Epstein JN (1998a) Revision and restandardization of the Conners' teacher rating scale (CTRS-R): factor structure, reliability and criterion validity. J Abnorm Child Psychol 26: 279291

Conners CK, Sitarenios G, Parker JDA, Epstein JN (1998b) The revised Conners' parent rating scale (CPRS-R): factor structure, reliability and criterion validity. J Abnorm Child Psychol 26: 257268

Dick DM, Viken RJ, Kaprio J, Pulkkinen L, Rose RJ (2005) Understanding the Covariation among Childhood Externalizing Symptoms: Genetic and Environmental Influences on Conduct Disorder, Attention Deficit Hyperactivity Disorder, and Oppositional Defiant Disorder Symptoms. J Abnorm Child Psychol 33: 219-229

Drabick DAG, Gadow KD, Sprafkin J (2006) Co-occurrence of conduct disorder and depression in a clinic-based sample of boys with ADHD. J Child Psychol Psychiat 47: 766-774

Ehringer MA, Rhee SH, Young S, Corley R, Hewitt JK (2006) Genetic and Environmental Contributions to Common Psychopathologies of Childhood and Adolescence: A Study of Twins and their Siblings. J Abnorm Child Psychol 34: 1-17

Eiraldi RB, Power TJ, Nezu CM (1997) Patterns of comorbidity associated with subtypes of attention-deficit/ hyperactivity disorder among 6 to 12year old children. J Am Acad Child Adolesc Psychiat 36: 503-514

Faraone SV, Asherson P, Image Consortium (2005a) The Molecular Genetics of Attention Deficit Hyperactivity Disorder:
A View from the IMAGE Project. Psychiatric Times August : 21-23

Faraone SV, Biederman J (1997) Do attention deficit hyperactivity disorder and major depression share familial risk factors? J Nerv Ment Dis 185: 533-541

Faraone SV, Biederman J, Chen WJ, Milberger S, Warburton R, Tsuang MT (1995) Genetic heterogeneity in attention-deficit hyperactivity disorder (ADHD): gender, psychiatric comorbidity, and maternal ADHD. J Abnorm Psychol 104: 334-345

Faraone SV, Biederman J, Friedman D (2000a) Validity of DSM-IV subtypes of attention-deficit/hyperactivity disorder: a family study perspective. J Am Acad Child Adolesc Psychiat 39: 300-307

Faraone SV, Biederman J, Jetton JG, Tsuang MT (1997) Attention deficit disorder and conduct disorder: longitudinal evidence for a familial subtype. Psychol Med 27: 291-300

Faraone SV, Biederman J, Keenan K, Tsuang MT (1991) Separation of DSM-III attention deficit disorder and conduct disorder: evidence from a family-genetic study of American child psychiatric patients. Psychol Med 21: 109-121

Faraone SV, Biederman J, Monuteaux MC (2000b) Attention-deficit disorder and conduct disorder in girls: evidence for a familial subtype. Biol Psychiat 48: 21-29

Faraone SV, Perlis RH, Doyle AE, Smoller JW, Goralnick JJ, Holmgren MA, Sklar P (2005b) Molecular Genetics of Attention Deficit Hyperactivity Disorder. Biol Psychiat 57: 1313-1323

Faraone SV, Sergeant JA, Gillberg C, Biederman J (2003) The worldwide prevalence of ADHD: is it an American condition? World Psychiatry 2: 104-113

Frick PJ, Lahey BB, Christ MG, Green S (1991) History of childhood behavior problems in biological relatives of boys 
with attention deficit hyperactivity disorder and conduct disorder. J Clin Child Psychol 20: 445-451

Gadow KD, Sprafkin J, Schneider J, Nolan EE, Schwartz J, Weiss MD (2007) ODD, ADHD, Versus ODD+ADHD in Clinic and Community Adults. J Atten Disord in press

Goodman R (1997) The strengths and difficulties questionnaire: a research note. J Child Psychol Psychiat 38: 581586

Goodman R, Stevenson J (1989) A twin study of hyperactivity - I. An examination of hyperactivity scores and categories derived from Rutter teacher and parent questionnaires. J Child Psychol Psychiat 30: 671-689

Greene RW, Biederman J, Zerwas S, Monuteaux MC, Goring JC, Faraone SV (2002) Psychiatric Comorbidity, Family Dysfunction, and Social Impairment in Referred Youth With Oppositional Defiant Disorder. Am J Psychiat 159: 1214-1224

Halperin JM (1991) The clinical assessment of attention. Int J Neurosci 58: 171-182

Hurtig $T$, Ebeing $H$, Taanila $A$, Miettunen $J$, Smalley SL, McGough J, Järvelin M-R, Moilanen I (2007) ADHD and comorbid disorders in relation to family environment and symptom severity. Eur Child Adolesc Psychiat 16: 362-369

Jain $M$, Palacio LG, Castellanos FX, Palacio JD, Pineda D, Restrepo MI, Munoz JF, Lopera F, Wallis D, Bailey-Wilson JE, Arcos-Burgos M, Muenkje M (2007) Attention-Deficit/Hyperactivity Disorder and Comorbid Disruptive Behavior Disorders: Evidence of Pleiotropy and New Susceptibility Loci. Biol. Psychiat 61: 1329-1339

Jensen PS, Martin D, Cantwell DP (1997) Comorbidity in ADHD: implications for research, practice and DSM-V. J Am
Acad Child Adolesc Psychiat 36: 10651079

Kirley A, Lowe N, Mullins C, McCarron M, Daly $G$, Waldman ID, Fitzgerald $M$, Gill M, Hawi Z (2004) Phenotype studies of the DRD4 gene polymorphisms in ADHD: association with oppositional defiant disorder and positive family history. Am J Med Genet Part B 131: 3842

Kratzer L, Hodgins S (1997) Adult outcomes of child conduct problems: a cohort study. J Abnorm Child Psychol 25: 65-81

Kuhne M, Schachar RJ, Tannock R (1997) Impact of comorbid oppositional or conduct problems on attention-deficit hyperactivity disorder. J Am Acad Child Adolesc Psychiat 36: 1715-1725

Kuntsi J, Stevenson J (2001) Psychological mechanisms in hyperactivity: II The role of genetic factors. J Child Psychol Psychiat 42: 211-219

Lahey BB, Piacentini J, McBurnett K, Stone P, Hartdagen S, Hynd G (1988) Psychopathology in the parents of children with conduct disorder and hyperactivity. J Am Acad Child Adolesc Psychiat 27: 163-170

Lahey BB, Russo MF, Walker JL (1989) Personality characteristics of the mothers of children with disruptive disorders. J Consult Clin Psychol 57: 512515

Lahey BB, Schwab-Stone M, Goodman SH, Waldman ID, Canino G, Rathouz PJ, Miller TL, Dennis KD, Bird $\mathrm{H}$, Jensen PS (2000) Age and gender differences in oppositional behavior and conduct problems: a cross-sectional household study of middle childhood and adolescence. J Abnorm Psychol 109: 488-503

Levy F, Bennett KS, Hartman CA, Hay DA, Sergeant JA (2006) A Twin Study of Conduct Disorder and ADHD: Is extreme 
Conduct Disorder different? In: Oades RD (ed) Attention-Deficit/Hyperactivity Disorder (AD/HD) and the Hyperkinetic Syndrome (HKS): Current Ideas and Ways Forward. Hauppauge, New York: Nova Science Publishing Inc, pp 23-34

Mathias CW, Furr RM, Daniel SS, Marsh DM, Shannon EE, Dougherty DM (2007) The relationship of inattentiveness, hyperactivity, and psychopathy among adolescents. Person Individ Diffs 43: 1333-1343

McGuffin P, Gottesman II (1985) Genetic influences on normal and abnormal development. In: Rutter $\mathrm{M}$, Hersov L (Eds) Child and adolescent psychiatry: modern approaches (2nd Ed.). Oxford: Blackwell Scientific, pp 17-33

Nadder TS, Rutter M, Silberg JL, Maes HH, Eaves LJ (2002) Genetic effects on the variation and co-variation of attention deficit-hyperactivity disorder (ADHD) and oppositional-defiant disorder/ conduct disorder (ODD/CD) symptomatologies across informant and occasion of measurement. Psychol Med 32: $39-53$

Nock MK, Kazdin AE, Hiripi E, Kessler RC (2006) Prevalence, subtypes, and correlates of DSM-IV conduct disorder in the National Comorbidity Survey Replication. Psychol Med 36: 699-710

Rasmussen ER, Neuman RJ, Heath AC, Levy F, Hay DA, Todd RD (2002) Replication of the latent class structure of attention-deficit/hyperactivity disorder (ADHD) subtypes in a sample of Australian twins. J Child Psychol Psychiat 43: 1018-1028

Rohde LA, Barbosa G, Polanczyk G, Eizirik $M$, Rasmussen ER, Neuman RJ, Todd RD (2001) Factor and latent class analysis of DSM-IV ADHD symptoms in a school sample of Brazilian adolescents. J Am Acad Child Adolesc Psychiat 40: 711-718
Rowe DC, Stever C, Giedinghagen LN, Gard JM, Cleveland HH, Terris ST, Mohr JH, Sherman S, Abramowitz A, Waldman ID (1998) Dopamine DRD4 receptor polymorphism and attention deficit hyperactivity disorder. Mol Psychiat 3: 419-426

Sattler JM (1992) Assessment of Children: Behavioral and Clinical Applications. San Diego: J. M. Sattler Publ. Inc

Schachar RJ, Tannock R (1995) Tests of four hypotheses for the comorbidity of attention-deficit hyperactivity disorder and conduct disorder. J Am Acad Child Adolesc Psychiat 34: 639-648

Schachar RJ, Wachsmuth R (1990) Oppositional disorder in children: a validation study comparing conduct disorder, oppositional disorder and normal control children. J Child Psychol Psychiat 31: 1089-1102

Shaw DS, Lacourse E, Nagin DS (2005) Developmental trajectories of conduct problems and hyperactivity from ages 2 to 10. J Child Psychol Psychiat 46: 931942

Silberg JL, Rutter M, Meyer J, Maes $\mathrm{H}$, Hewitt J, Simonoff E, Pickles A, Loeber $R$, Eaves L (1996) Genetic and environmental influences on the covariation between hyperactivity and conduct disturbance in juvenile twins. J Child Psychol Psychiat 37: 803-816

Simonoff E, Pickles A, Meyer JM, Silberg JL, Maes HH, Loeber R, Rutter M, Hewitt JK, Eaves $L$ (1997) The Virginia Twin Study of Adolescent Behavioral Development. Influences of age, sex, and impairment on rates of disorder. Arch Gen Psychiat 54: 801-808

Smith AB, Taylor EA (2006) Response inhibition and hyperactivity in clinical and non-clinical populations: a metaanalysis using the stop task. In: Oades RD (Ed) Attention-Deficit/Hyperactivity 
Disorder and the Hyperkinetic Syndrome: Current Ideas and Ways Forward. Hauppauge, New York: Nova Science Publishing Inc, pp 203-225

Stewart MA, De Blois CS, Cummings C (1980) Psychiatric disorder in the parents of hyperactive boys and those with conduct disorder. J Child Psychol Psychiat 21: 283-292

Szatmari P, Boyle M, Offord D (1993) Familial aggregation of emotional and behavioral problems of childhood in the general population. Am J Psychiat 150: 1398-1403

Taylor EA (1998) Clinical foundations of hyperactivity research. Behav Brain Res 94: 11-24

Taylor EA, Sandberg S, Thorley G, Giles S (1991) The epidemiology of childhood hyperactivity. Oxford, UK: Oxford University Press

Thapar A, Harrington R, McGuffin P (2001) Examining the comorbidity of ADHDrelated behaviours and conduct problems using a twin study design. Br J Psychiat 179: 224-229

Thapar A, Holmes J, Poulton K, Harrington $R$ (1999) Genetic basis of attention deficit and hyperactivity. $\mathrm{Br} J$ Psychiat 174: 105-111

Todd RD, Sitdhiraksa N, Reich W, Ji TH-C, Joyner CA, Heath AC, Neuman RJ (2002) Discrimination of DSM-IV and latent class attention-deficit/hyperactivity disorder subtypes by educational and cognitive performance in a populationbased sample of child and adolescent twins. J Am Acad Child Adolesc Psychiat 41: $820-828$

Vierikko E, Pulkkinen L, Kaprio J, Rose RJ (2004) Genetic and environmental influences on the relationship between aggression and Hyperactivity-impulsivity as rated by teachers and parents. Twin Research 7: 261-274
Volk HE, Henderson C, Neuman RJ, Todd RD (2006) Validation of PopulationBased ADHD Subtypes and Identification of Three Clinically Impaired Subtypes. Am J Med Genet Part B 141B: 312-318

Willcutt EG, Pennington BF, DeFries JC (2000) Etiology of inattention and hyperactivity/impulsivity in a community sample of twins with learning difficulties. J Abnorm Child Psychol 28: 149-159

Woerner W, Becker A, Rothenberger A (2004) Normative data and scale properties of the German parent SDQ. Eur Child Adolesc Psychiat 13: 3-11 